\title{
Genetic analysis of reciprocal differences in the inheritance of in vitro characters in pearl millet
}

\author{
Valluri V Satyavathi ${ }^{1, *}$, V. Manga ${ }^{1}$, Muktinutalapati V. Subba Rao ${ }^{1}$, and Malladi Chittibabu ${ }^{2}$ \\ ${ }^{1}$ Department of Botany, Andhra University, Visakhapatnam, India. \\ ${ }^{2}$ Department of Statistics, Andhra University, Visakhapatnam, India.
}

\begin{abstract}
Reciprocal differences persist in nature because of the unequal contribution of cytoplasmic determinants from male and female gametes to the zygote. The inheritance of genetic differences is an important factor that influences various traits, including somatic embryogenesis and regeneration in vitro. In this report, we estimate the cytoplasmic and maternal effects in pearl millet and their adequacy in describing the observed reciprocal differences based on an in depth study of the parents, $F_{2} s$ and reciprocal backcross progenies needed for fitting genetical models. Our study revealed that of the two characters examined, embryogenic callus quantity and regeneration frequency, the former showed a greater proportion of cytoplasmic nuclear interaction whereas the latter showed a greater role of nuclear factors. Additive-maternal effects influenced total callus quantity and dominance-maternal effects influenced total callus quantity, embryogenic callus quantity and regeneration frequency. Dwarfing was associated with the production of large quantities of embryogenic callus that had visually recognizable characteristics. The phenotypic nature of dwarf parents (green dwarf with long narrow leaves) with a genetic basis for a given character controlled by nuclear and cytoplasmic determinants can be exploited for other breeding programs.
\end{abstract}

Keywords: cytoplasmic inheritance, $\mathrm{d}_{2}$ dwarf, in vitro regeneration, pearl millet, reciprocal differences.

Received: January 20, 2015; Accepted: May 18, 2015.

\section{Introduction}

In vitro characters are often used in combination with other agronomic traits for crop improvement programs. The availability of an efficient in vitro plant regeneration system is a prerequisite for the successful application of any biotechnological tool in plant breeding. Ikeuchi et al. (2013) provided an overview of callus and plant formation in vitro and described in detail the genetic and epigenetic mechanisms that induce or repress callus induction. An obvious challenge for tissue culture researchers is to develop in vitro technologies for faster, more predictable production of embryogenesis and plant regeneration. Despite all numerous technological advances, the successful application of plant tissue culture techniques to crop improvement is still dependent on understanding the genetic basis for 'in vitro aptitude' that will help to predict the in vitro responses of genotypes for further selection. The influence of genotype on in vitro characters and the genetic basis of the in vitro response have been analyzed in several plant systems,

Send correspondence to Valluri V. Satyavathi. Department of Botany, Andhra University, Visakhapatnam 530003, India. E-mail: vsatya@cdfd.org.in; vallurisatyavathi@gmail.com

"Current address: Laboratory of Molecular Genetics, APEDACDFD, Centre for DNA Fingerprinting and Diagnostics, Nampally, Hyderabad 500001, India. including pearl millet (Pueschel et al., 2003; Satyavathi et al., 2006; Dodig et al., 2008; Chakravarthi et al., 2010; Etedal et al., 2012; Wang et al., 2013).

The study of the inheritance of genotypic differences is often complicated because of the occurrence of reciprocal differences (Powell and Caligari, 1987). The analysis of cytoplasmic factors in understanding the underlying modes of transmission of in vitro traits is more complicated than for nuclear factors. Various studies have examined the influence of cytoplasmic and/or maternal inheritance and the interaction between nuclear and cytoplasmic factors on in vitro somatic embryogenesis and morphogenesis in wheat (Ekiz and Konzak, 1991; Taylor and Veilleux, 1992; Bebeli, 1995; Ben-Amer and Boner, 1997), maize (Tomes and Smith, 1985; Willman et al., 1989; Ge et al., 1994), barley (Foroughi-Wehr et al., 1982; Powell and Caligari, 1987; Hou et al., 1994), rice (Abe and Futsuhara, 1991), red clover (Keyes et al., 1980), Brassica (Narasimhulu et al., 1989), tomato (Singsit and Veilleux, 1989), Medicago (Walton and Brown, 1988; Wan et al., 1988), Allium ampeloprasum L. (Silverstand et al., 1995) and Desmodium (Krottje et al., 1996).

The basis of the reciprocal differences in in vitro responses may be cytoplasmic factors, the maternal plant genotype or the segregation of nuclear factors. Discrimination between the first two phenomena becomes necessary in the 
analysis of reciprocal differences. When the female parent influences the phenotype of the progeny regardless of the latter's genotype, it is considered as maternal effect, whereas in cytoplasmic inheritance the mitochondrial DNAs transmitted to the progeny will have an effect on the phenotype of the organism (Henry et al., 1994). Powell (1988), using the biometrical analysis of Hayman (1954a), analyzed reciprocal differences in barley cultures attributed to component ' $c$ ' (average reciprocal differences) to determine the percentage of green and albino plant production. This group also estimated component ' $d$ ' (further reciprocal differences that were not accounted for by $c$ ) to assess the percentage corresponding to anthers and green plant production.

Among dicots, Narasimhulu et al. (1989) reported significant differences caused by cytoplasmic factors during shoot morphogenesis in Brassica carinata. Pueschel et al. (2003) analyzed the genetic control of the in vitro response of Cyclamen persicum genotypes with and without embryogenic potential. Based on the $\mathrm{F}_{2}$ segregation ratio, these authors postulated two major dominant genes with epistatic interaction for regeneration capacity.

Among monocots, Li et al. (2007) attempted to clarify the inheritance pattern of callus browning using reciprocal segregating $\mathrm{F}_{2}$ populations and two $\mathrm{BC}_{1}$ populations derived from crosses between two inbred rice lines. Genetic analysis of callus browning and a mapbased cloning strategy were used to locate the browning gene.

In wheat, Dodig et al. (2008) used correlation and path coefficient analyses to study associations between tissue culture and agronomic traits. Path coefficient analysis revealed that grain yield had the highest positive direct effect on regenerative calli and plant number per embryo. These authors observed a strong influence of genotype on tissue culture traits evaluated from immature embryos of wheat genotypes.

Mythili et al. (1997) suggested the presence of reciprocal differences for in vitro responses in pearl millet. However, no detailed analysis of such reciprocal differences has been reported. Subsequently, Satyavathi et al. (2006), in a study of the genetics of in vitro characters in pearl millet, reported the occurrence of reciprocal differences for all four of the in vitro characters they examined in reciprocal hybrids involving two inbred lines, $P_{3}\left(d_{2}\right.$ dwarf) and $\mathrm{P}_{4}$ (purple pigmentation in plant parts) with phenotypic marker characters. This finding prompted use of the $F_{2}$ and backcross progenies of these particular crosses to establish the cause of the reciprocal differences based on the method by Hayman (1954a). The aim of the present study was to investigate the underlying genetic basis of reciprocal differences for callus characters and in vitro morphogenesis using biometrical genetical analyses in pearl millet.

\section{Material and Methods}

\section{Plant material}

Five inbred lines of pearl millet, Pennisetum glaucum (L.) R.Br., with different phenotypic marker characters were grown in the experimental farm of the Botany Department at Andhra University, Visakhapatnam, and have been maintained through selfing and sib mating for at least 8-10 generations. The five inbred lines were crossed in a diallel manner and the genetics of their in vitro response was studied (Satyavathi VV, 1998, PhD thesis, Andhra University, Visakhapatnam, India). Two parents, $\mathrm{P}_{3}\left(d_{2}\right.$ dwarf measuring $80-120 \mathrm{~cm}$ ) and $\mathrm{P}_{4}$ (IP 3128 with purple pigmentation in the internodes, leaf sheath, midrib and margin) showing reciprocal differences for all of the in vitro characters studied, were crossed reciprocally and the $F_{1}$ hybrids were backcrossed reciprocally with the respective parents. The $\mathrm{F}_{1} \mathrm{~S}$ were selfed to produce eight $\mathrm{F}_{2}$ populations.

\section{Explant type and culture conditions}

For callus initiation, segments of immature inflorescences at stage I (Mythili et al., 1997), still enclosed within the flag and boot leaves, were used. The stage of inflorescence was selected based on the relative distance between the flag and boot leaves and the two leaves subtending them. The nutrient medium and culture conditions used and the data collection for the in vitro characters were essentially as described by Satyavathi et al. (2006). Briefly, immature inflorescences were surface sterilized with $30 \%$ sodium hypochlorite solution for $30 \mathrm{~min}$ and washed three times with sterile distilled water. Each inflorescence measuring about $3-5 \mathrm{~cm}$ in length and having a pinhead-sized spikelet primordial was excised and cut into $0.5-0.6 \mathrm{~cm}$ discs. These discs (explants) were then placed on glass Petri dishes containing 20-25 mL of solidified Murashige and Skoog (1962) medium supplemented with $1 \mathrm{mg}$ of 2,4Dichlorophenoxyacetic acid (2,4-D) per $\mathrm{ml}$ at a density of 4-6 discs per dish. The dishes were sealed with parafilm and incubated at $26 \pm 2^{\circ} \mathrm{C}$ in the dark for up to six weeks for callus induction. For regeneration, the callus pieces (embryogenic callus, referred to as E callus) were transferred to MSKB medium (MS medium with $0.25 \mathrm{mg} / \mathrm{ml}$ each of kinetin and 6-Benzyladenine) at the end of sixth week after inoculation. The cultures were incubated under $16 \mathrm{~h}: 8 \mathrm{~h}$ light:dark photoperiod at a light intensity of 1600 lux provided by white florescent tubes.

\section{Experimental design}

Six to ten plants from each of the two inbred lines, their two reciprocal $F_{1} s$, about 100 plants from each of the four $F_{1} s$ and about 50 plants from each of the eight backcross populations were grown in the field in a randomized block design with two replications. Plants in the field as well as the arrangement of Petri dishes (each dish containing segments from one inflorescence representing a 
field grown plant) on the culture racks followed the same randomized pattern. The data were collected after six weeks of culture and included (1) the total quantity of calli, i.e., embryogenic and non-embryogenic calli measured using thin, transparent polythene graph paper and expressed in $\mathrm{cm}^{2}$, (2) the quantity of embryogenic calli expressed as a percentage of embryogenic callus area relative to the total callus area, (3) the callus growth rate defined as an increase in callus fresh weight at 3-6 week intervals, and (4) the frequency of regeneration scored as the number of plantlets produced per explant on MSKB medium after nine weeks.

\section{Data analysis}

In a previous study (Satyavathi et al., 2006), we ran a $5 \times 5$ diallel analysis of five pearl millet inbred lines using four in vitro characters. The significance of the mean squares and the effects of general combining ability (GCA), specific combining ability (SCA) and reciprocals were analyzed using the combining ability analyses of method I described by Griffing (1956), based on Eisenhart's fixed effect model (model I) and the following assumptions: normal diploid segregation, absence of maternal effects, independent action of non-allelic genes, no multiple alleles, homozygous parents, independent distribution of genes between parents and inbreeding coefficient equal to 1 .

In the present study, the data were further analyzed as described by Hayman (1954a) and the five main effects were calculated according to Mather and Jinks (1982). The components $c$ (average reciprocal differences) and $d$ (further reciprocal differences not accounted for by $c$ ) were estimated. The mean values for each of the four in vitro characters in the reciprocal hybrids $\left(\mathrm{F}_{1} \mathrm{~s}\right)$ were analyzed using Student's $t$-test to check for individual differences in each of the ten hybrid combinations. Reciprocal differences between the crosses were examined using Student's $t$-test. The means and variances for individual plant data were estimated for each generation separately and a generation mean analysis was undertaken. The parents, $\mathrm{F}_{1}, \mathrm{~F}_{2}, \mathrm{BC}_{1} \mathrm{~F}_{1}$, $\mathrm{BC}_{2} \mathrm{~F}_{1}$ and their reciprocals were used to fit a simple additive-dominance model in the generation means approach. A joint scaling test (Cavalli, 1952) was done. The model proposed by Hayman (1958), which estimates the mean $(m)$, additive $(d)$ and dominance $(h)$ effects, and those caused by their interactions, $i, j$ and $l$, was used. The genetic model for estimating additive- and dominance-genetic effects in the presence of maternal effects as given by Mather and Jinks (1982) was followed. This model provides estimates of the contribution of the cytoplasm (c), interaction between cytoplasm and the additive nuclear-determined effect $(c d)$, interaction between cytoplasm and the dominance nucleardetermined effect (ch), maternal effects traceable to the additive genetic component $(\mathrm{dm})$, and dominance effects of the maternal genotype $(\mathrm{hm})$. The expectations for the family means in terms of genetic parameters for nuclear and cytoplasmic components, as well as for maternal effects as given by Powell and Caligari (1987), were applied to the four in vitro characters. The quantity of embryogenic calli and frequency of regeneration showed a good fit to the genetic model. The different parameters were estimated from the means of the 16 generations and a comparison of the generation mean with the expected values was done using the joint sealing test. The significance of each of the estimated parameters and the adequacy of the additivedominance model were tested using standard procedures (Mather and Jinks, 1982).

\section{Results}

In the present study, in vitro regeneration of pearl millet was obtained by culturing immature inflorescences as described earlier (Mythili et al., 1997; Satyavathi et al., 2006). Plant regeneration was via somatic embryogenesis. Histological examination of the explants showed cellular proliferation beneath the outer layer of rachis and also from the base of the spikelet primordia. The calli obtained were of two types: embryogenic (E callus) and non-embryogenic (NE callus). At the end of the sixth week after inoculation, segments of embryogenic calli were transferred to regeneration medium. Embryoid formation was observed one week after the transfer of embryogenic calli to regeneration medium. These embryoids first appeared as ovoid masses of cells that later developed into globular proembryoids to subsequently form heart-shaped embryoids. At this stage, the somatic embryoids appeared as white opaque protuberances with collar-like structures; these somatic embryos showed root-shoot differentiation and developed into plantlets (Figure 1).

The calli obtained from $\mathrm{P}_{3}$ and $\mathrm{P}_{4}$ parents were distinguishable, with the $\mathrm{P}_{3}$ parent showing highly compact, nodular calli while the $\mathrm{P}_{4}$ parent showed mostly crystalline, transluscent calli. In the hybrids involving these two parents, the reciprocal differences were significant for all of the four in vitro characters studied. The quantity of embryogenic and non-embryogenic portions of calli and the number of regenerated plantlets in the reciprocal hybrids involving $\mathrm{P}_{3}$ and $\mathrm{P}_{4}$ are shown in Figure 2.

The Hayman (1954a) analysis for a $5 \times 5$ diallel set of pearl millet lines revealed items ' $c$ ' and ' $d$ ' to be significant for the quantity and frequency of regeneration of embryogenic calli, whereas only item ' $d$ ' was significant for total quantity of calli and growth rate (Table 1). Among the ten hybrid combinations from a $5 \times 5$ diallel set, the reciprocal differences were significant for all of the four in vitro characters in the cross involving $\mathrm{P}_{3}$ and $\mathrm{P}_{4}$ inbreds. In the remaining hybrids, the reciprocal differences were significant for only one or two characters (Table 2). Consequently, the cross involving $\mathrm{P}_{3}$ and $\mathrm{P}_{4}$ was chosen for a detailed analysis of the reciprocal differences. One set of crosses, viz., $\mathrm{P}_{3} \mathrm{XP}_{4}$ and its reciprocal $\mathrm{P}_{4} \mathrm{xP}_{3}$, was used to produce the reciprocal $\mathrm{F}_{2} \mathrm{~S}$ as well as reciprocal backcrosses, thus providing 16 families. The average values for each 

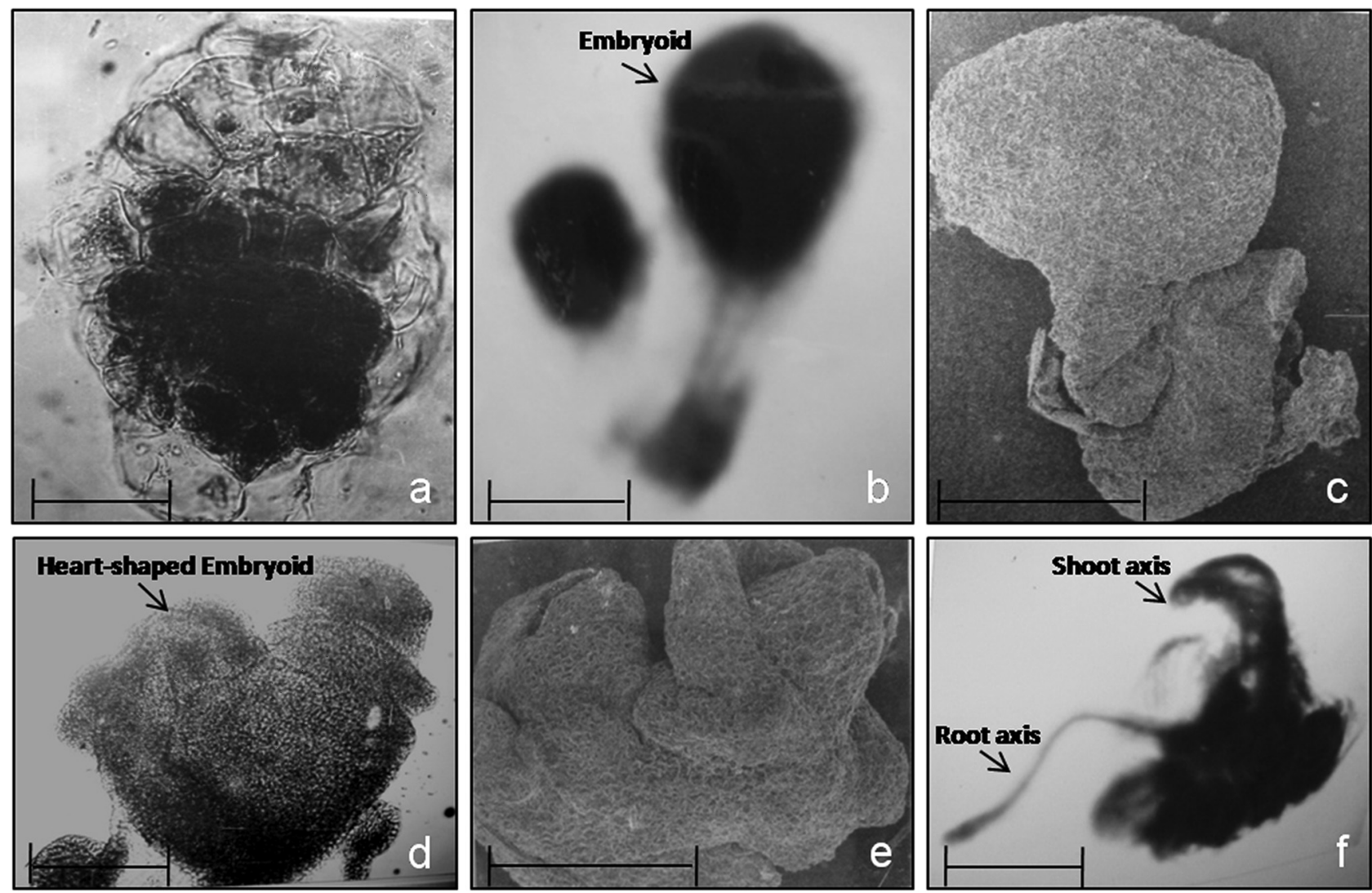

Figure 1 - Various developmental stages during somatic embryogenesis in pearl millet. (A) A single ovoid proembryoid, (B) Stalked globular embryoids, (C) Scanning electron micrograph of a stalked globular embryoid, (D) Heart-shaped somatic embryo, (E) Scanning electron micrograph of a somatic embryo with collar-like scutellum (200x), and (F) Somatic embryo with root and shoot primordia. Scale bar $=10 \mu \mathrm{m}$.

of the four in vitro characters of the 16 families were examined.
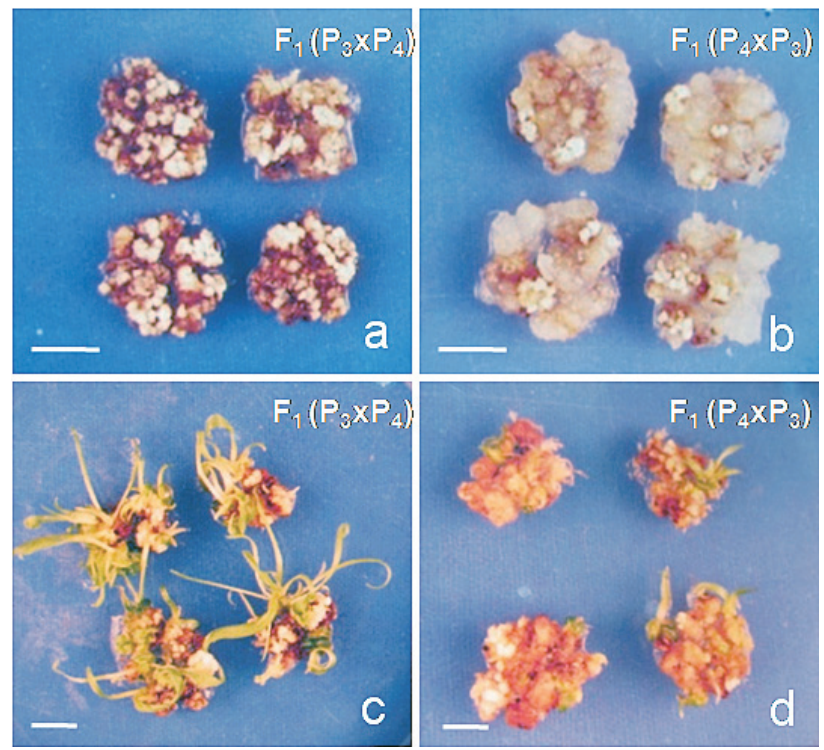

Figure 2 - Differences in the quantities of embryogenic (A) and nonembryogenic (B) portions of callus and in the number of regenerated plantlets in the corresponding hybrid $\mathrm{F}_{1}\left(\mathrm{P}_{3} \times \mathrm{P}_{4}\right)(\mathrm{C})$ and reciprocal hybrid $\mathrm{F}_{1}\left(\mathrm{P}_{4} \times \mathrm{P}_{3}\right)(\mathrm{D})$ involving the $\mathrm{P}_{3}$ and $\mathrm{P}_{4}$ inbred lines. Scale bar $=100 \mu \mathrm{m}$.
Students $t$-test, used to detect differences in the means of each of the four in vitro characters, revealed significant differences between $\mathrm{P}_{3}$ and $\mathrm{P}_{4}$, between reciprocal $\mathrm{F}_{1} \mathrm{~S}$ $\left(\mathrm{P}_{3} \mathrm{XP}_{4}\right.$ and $\left.\mathrm{P}_{4} \mathrm{XP}_{3}\right)$, and between reciprocal backcrosses for $\mathrm{BC}_{1}$ (callus growth rate) and $\mathrm{BC}_{2}$ (total callus quantity) (Table 3). A two-way ANOVA used to assess the differences for each character revealed significant differences ( $\mathrm{p}$ $<0.05$ ) among the 16 families as expected, but no differences between the replications ( $p>0.05)$; a significant interaction factor $(\mathrm{p}<0.01)$ was also observed (data not shown).

Embryogenic callus quantity and regeneration frequency showed a good fit to the genetic model, although the chi-square test of the goodness of fit was not significant ( $p$ $>0.01)$; the other two characters did not fit the model ( $\mathrm{p}<$ 0.01 ) (Table 4). For embryogenic callus quantity, the parameters $d, j$ and $c d$, representing the additive effect, additive $\mathrm{x}$ dominance interactions and the interaction between cytoplasmic and nuclear-determined effects, respectively, were significant. For the regeneration frequency, all of the parameters that provided estimates of the main effects and that represented the nuclear genetic contributions to the family means were found to be significant. The dominance increment of loci $(h)$ for the nuclear genetic contribution was positive, while the ' $l$ ' increment for pairs of loci was 
Table 1 - Hayman analyses of variance for the four in vitro characters obtained from a $5 \times 5$ diallel analysis.

\begin{tabular}{lccccc}
\hline & & \multicolumn{3}{c}{ Mean squares } \\
\cline { 3 - 6 } Item & Degrees of freedom & Total callus quantity & Embryogenic callus quantity & Callus growth rate & Regeneration frequency \\
\hline$a$ & 4 & $0.0209^{*}$ & $155.5555^{*}$ & $0.0394^{*}$ & $6.6107^{*}$ \\
$b$ & 10 & 0.0078 & $61.6698^{*}$ & $0.0151^{*}$ & $4.6833^{*}$ \\
$b_{1}$ & 1 & 0.0006 & 1.5819 & 0.0505 & $3.0489^{*}$ \\
$b_{2}$ & 4 & $0.0185^{*}$ & $61.4082^{*}$ & $0.0214^{*}$ & $5.6812^{*}$ \\
$b_{3}$ & 5 & 0.0074 & $73.8966^{*}$ & 0.0029 & $4.2119^{*}$ \\
$c$ & 4 & 0.0134 & $78.6379^{*}$ & 0.0023 & $0.4479^{*}$ \\
$d$ & 6 & $0.0057^{*}$ & $13.0646^{*}$ & $0.0075^{*}$ & $0.7657^{*}$ \\
\hline
\end{tabular}

$a$ - additive genetic variation, $b$ - dominance variation, $b_{1}$ - mean dominance deviation, i.e., the overall difference between the $\mathrm{F}_{1} \mathrm{~s}$ compared to their mid-parent values, $b_{2}$-the variation in mean dominance deviations of the $\mathrm{F}_{1} \mathrm{~s}$ from their mid-parent values within each array, over arrays, $b_{3}$ - dominance deviations that are unique to individual $\mathrm{F}_{1} \mathrm{~s}, c$-average reciprocal differences, $d$ - further reciprocal differences not accounted for by $c$. Each item was tested against its own block interaction. ${ }^{*} \mathrm{p}<0.05$.

Table 2 - Reciprocal differences for the four in vitro characters in the different crosses $\left(\mathrm{F}_{1} \mathrm{~s}\right)$.

\begin{tabular}{|c|c|c|c|c|c|c|c|c|}
\hline \multirow[b]{2}{*}{ Cross } & \multicolumn{2}{|c|}{ Total callus quantity } & \multicolumn{2}{|c|}{ Embryogenic callus quantity } & \multicolumn{2}{|c|}{ Callus growth rate } & \multicolumn{2}{|c|}{ Regeneration frequency } \\
\hline & $\mathrm{t}$ value & df & $\mathrm{t}$ value & df & $\mathrm{t}$ value & $\mathrm{df}$ & t value & $\mathrm{df}$ \\
\hline $\mathrm{P}_{1} \mathrm{xP}_{2}$ vs $\mathrm{P}_{2} \mathrm{xP}_{1}$ & 1.1157 & 49.5 & $2.0040^{*}$ & 55.9 & 0.8185 & 10 & 0.2199 & 55 \\
\hline $\mathrm{P}_{1} \mathrm{xP}_{3}$ vs $\mathrm{P}_{3} \mathrm{xP}_{1}$ & $3.8631 *$ & 66.9 & $2.9768^{*}$ & 76.0 & 0.0207 & 11 & 0.8213 & 61 \\
\hline $\mathrm{P}_{1} \mathrm{xP}_{4}$ vs $\mathrm{P}_{4} \mathrm{xP}_{1}$ & 1.1050 & 48.0 & 1.7026 & 72.0 & 1.6554 & 9 & $2.0053^{*}$ & 61 \\
\hline $\mathrm{P}_{1} \mathrm{xP}_{5}$ vs $\mathrm{P}_{5} \mathrm{xP}_{1}$ & 1.6678 & 78.5 & 0.9592 & 82.0 & $3.9175^{*}$ & 9 & 0.9362 & 56 \\
\hline $\mathrm{P}_{2} \mathrm{XP}_{3}$ vs $\mathrm{P}_{3} \mathrm{xP}_{2}$ & $2.4558^{*}$ & 90.0 & 0.1107 & 71.3 & 1.0071 & 10 & 0.8820 & 66 \\
\hline $\mathrm{P}_{2} \mathrm{XP}_{4}$ vs $\mathrm{P}_{4} \mathrm{xP}_{2}$ & 0.1946 & 56.7 & 0.4315 & 79.5 & 1.9092 & 10 & 0.3663 & 49 \\
\hline $\mathrm{P}_{2} \mathrm{xP}_{5}$ vs $\mathrm{P}_{5} \mathrm{xP}_{2}$ & $2.0833 *$ & 70.0 & 0.2652 & 66.0 & 0.8549 & 6.2 & 0.8589 & 67 \\
\hline $\mathrm{P}_{3} \mathrm{XP}_{4}$ vs $\mathrm{P}_{4} \mathrm{xP}_{3}$ & $3.7678 *$ & 68.7 & $4.0852 *$ & 79.0 & $3.7583^{*}$ & 9 & $2.0285^{*}$ & 49 \\
\hline $\mathrm{P}_{3} \mathrm{xP}_{5}$ vs $\mathrm{P}_{5} \mathrm{xP}_{3}$ & $6.2262 *$ & 68.7 & $3.0623 *$ & 63.5 & 1.5066 & 10 & 0.1634 & 48 \\
\hline $\mathrm{P}_{4} \mathrm{xP}_{5}$ vs $\mathrm{P}_{5} \mathrm{xP}_{4}$ & $3.7778 *$ & 58.0 & 0.6842 & 50.6 & 0.8956 & 10 & 0.5583 & 51 \\
\hline
\end{tabular}

df calculated from Behren-Fisher's conversion. *p $<0.05$.

negative. The maternal effects included an additive genetic component $(\mathrm{dm})$ and dominance $(\mathrm{hm})$; the former affected total callus quantity, whereas the latter affected total callus quantity, embryogenic callus quantity and regeneration frequency.

\section{Discussion}

Cytoplasmic inheritance results in persistent reciprocal differences and reflects an unequal contribution of cytoplasmic determinants from male and female gametes to the zygote (Jinks, 1964). The maternal tissue effects are transient and change with the genotype of the mother. Since the cytoplasmic component includes either the chloroplast or mitochondrial DNA, a distinction between maternal and cytoplasmic modes of inheritance becomes necessary. This distinction is also important in order to manipulate the particular character, depending on its inheritance patterns. An in-depth study of the progenies other than the parents and $\mathrm{F}_{1} \mathrm{~S}$ (that is $\mathrm{F}_{2} \mathrm{~S}$ and backcrosses) is required when fitting ge- netic models that allow estimation of cytoplasmic and maternal effects and their adequacy in describing the observed reciprocal differences.

In a previous study, the ANOVA of genetic components from a $5 \times 5$ diallel cross revealed that GCA and SCA were significant $(\mathrm{p}<0.05)$ for the four in vitro characters studied, namely total callus quantity, embryogenic callus quantity, callus growth rate and frequency of regeneration (Satyavathi VV, 1998, PhD thesis, Andhra University, Visakhapatnam, India). GCA analysis indicated $\mathrm{P}_{4}$ as the best general combiner for total callus quantity and growth rate, $\mathrm{P}_{3}$ for embryogenic callus quantity, and $\mathrm{P}_{1}$ as well as $\mathrm{P}_{3}$ for regeneration frequency. SCA analysis revealed that some of the crosses $\left(\mathrm{P}_{1} \mathrm{XP}_{3}, \mathrm{P}_{3} \mathrm{XP}_{4}\right.$ and $\left.\mathrm{P}_{3} \mathrm{XP}_{5}\right)$ were the best specific combinations for one or more of the in vitro characters studied. In general, hybrids involving two poor general combiners showed better SCA effects. For callus growth rate and regeneration frequency, combinations of one better and one poor combiner produced better SCA effects. Similar GCA and SCA effects have been reported in 
Table 3 - Comparison of the average values of the two parents and corresponding reciprocal populations of $\mathrm{F}_{1} \mathrm{~s}, \mathrm{~F}_{2} \mathrm{~S}$ and backcrosses.

\begin{tabular}{|c|c|c|c|c|c|c|c|c|}
\hline \multirow[b]{2}{*}{ Population } & \multicolumn{2}{|c|}{ Total callus quantity } & \multicolumn{2}{|c|}{ Embryogenic callus quantity } & \multicolumn{2}{|c|}{ Callus growth rate } & \multicolumn{2}{|c|}{ Regeneration frequency } \\
\hline & $\mathrm{t}$ value & df & $\mathrm{t}$ value & df & $\mathrm{t}$ value & df & t value & df \\
\hline Parents $\mathrm{P}_{3}$ vs $\mathrm{P}_{4}$ & $7.1459 *$ & 10 & $9.4947^{*}$ & 10 & $9.9550 *$ & 10 & $8.6273^{*}$ & 10 \\
\hline $\mathrm{F}_{1}\left(\mathrm{P}_{3} \mathrm{XP}_{4}\right)$ vs $\mathrm{F}_{1}\left(\mathrm{P}_{4} \times \mathrm{P}_{3}\right)$ & $3.1727^{*}$ & 9 & $2.4650^{*}$ & 6.7 & $3.2509^{*}$ & 5.2 & $2.9635^{*}$ & 9 \\
\hline $\mathrm{F}_{2}\left(\mathrm{P}_{3} \times \mathrm{P}_{4}\right) \times\left(\mathrm{P}_{3} \times \mathrm{P}_{4}\right)$ vs $\left(\mathrm{P}_{4} \times \mathrm{P}_{3}\right) \times\left(\mathrm{P}_{4} \times \mathrm{P}_{3}\right)$ & 1.1015 & 198 & 1.8707 & 198 & 1.2970 & 192 & 1.0463 & 197 \\
\hline $\mathrm{F}_{2}\left(\mathrm{P}_{3} \mathrm{XP}_{4}\right) \times\left(\mathrm{P}_{4} \times \mathrm{P}_{3}\right)$ vs $\left(\mathrm{P}_{4} \times \mathrm{P}_{3}\right) \times\left(\mathrm{P}_{3} \mathrm{xP}_{4}\right)$ & 0.7636 & 187 & 0.9143 & 185 & 1.0214 & 146.3 & 0.5181 & 173 \\
\hline $\mathrm{BC}_{1}\left(\mathrm{P}_{3} \mathrm{x}\left(\mathrm{P}_{3} \mathrm{xP}_{4}\right)\right.$ vs $\left.\left(\mathrm{P}_{3} \mathrm{xP}_{4}\right) \mathrm{xP}_{3}\right)$ & 0.1773 & 83 & 0.3511 & 83 & $2.7090 *$ & 50.2 & 0.5573 & 81 \\
\hline $\mathrm{BC}_{1}\left(\mathrm{P}_{3} \times \mathrm{P}_{4} \times \mathrm{P}_{3}\right)$ vs $\left.\left(\mathrm{P}_{4} \mathrm{xP}_{3}\right) \mathrm{xP}_{3}\right)$ & 0.3147 & 96 & 0.6032 & 96 & $3.4493 *$ & 52.1 & 1.9679 & 93 \\
\hline $\mathrm{BC}_{2} \mathrm{P}_{4} \mathrm{x}\left(\mathrm{P}_{3} \mathrm{xP}_{4}\right)$ vs $\left(\mathrm{P}_{3} \mathrm{xP}_{4}\right) \mathrm{xP}_{4}$ & $2.5505^{*}$ & 72.8 & 1.3323 & 75 & 1.8129 & 64.7 & 0.5853 & 74 \\
\hline $\mathrm{BC}_{2} \mathrm{P}_{4} \mathrm{x}\left(\mathrm{P}_{4} \times \mathrm{P}_{3}\right)$ vs $\left(\mathrm{P}_{4} \mathrm{xP}_{3}\right) \mathrm{xP}_{4}$ & $2.6741^{*}$ & 63.6 & $2.7113^{*}$ & 63.4 & 0.0010 & 65 & 1.5185 & 65 \\
\hline
\end{tabular}

df calculated from Behren-Fisher's conversion. *p $<0.05$.

Table 4 - Estimates of the genetic parameters for nuclear and cytoplasmic components and chi-square values for the four in vitro characters

\begin{tabular}{lcccccccc}
\hline & \multicolumn{2}{c}{ Total callus quantity } & \multicolumn{2}{c}{ Embryogenic callus quantity } & \multicolumn{2}{c}{ Callus growth rate } & \multicolumn{2}{c}{ Regeneration frequency } \\
\cline { 2 - 8 } Parameter & Estimate & $\mathrm{t}$ value & Estimate & $\mathrm{t}$ value & Estimate & $\mathrm{t}$ value & Estimates & $\mathrm{t}$ value \\
\hline$m$ & $1.4784 \pm 0.2777$ & 5.3227 & $15.6168 \pm 4.7491$ & $3.2884^{*}$ & $1.1903 \pm 0.1914$ & 6.2183 & $0.1903 \pm 0.3327$ & 0.5720 \\
$d$ & $0.7655 \pm 0.2403$ & 3.1847 & $21.0579 \pm 4.5716$ & $4.6063^{*}$ & $-0.5212 \pm 0.1520$ & -3.4281 & $-0.7862 \pm 0.2229$ & $-3.5268^{*}$ \\
$h$ & $1.7179 \pm 0.4257$ & 4.0336 & $9.3529 \pm 7.5090$ & 1.2455 & $-0.8066 \pm 0.3155$ & -2.5565 & $1.9158 \pm 0.5298$ & $3.6163^{*}$ \\
$i$ & $0.5156 \pm 0.2522$ & 2.0447 & $4.0013 \pm 4.1421$ & 0.9660 & $0.0381 \pm 0.1981$ & 0.2024 & $1.0831 \pm 0.3054$ & $3.5467 *$ \\
$j$ & $-1.0542 \pm 0.4326$ & -2.4370 & $-24.0144 \pm 8.4691$ & $-2.8355^{*}$ & $0.5554 \pm 0.2704$ & 2.0539 & $1.5378 \pm 0.3229$ & $4.7611^{*}$ \\
$l$ & $-0.7715 \pm 0.2064$ & -3.7374 & $-3.1369 \pm 4.1760$ & -0.7511 & $1.0253 \pm 0.1751$ & 5.8563 & $-0.7404 \pm 0.2583$ & $-2.8666 *$ \\
$c$ & $0.3394 \pm 0.1711$ & 1.9837 & $6.9015 \pm 3.6373$ & 1.8974 & $-0.0755 \pm 0.1276$ & -0.5918 & $-0.2864 \pm 0.1416$ & -2.0229 \\
$c d$ & $0.2090 \pm 0.1045$ & 1.9989 & $-4.1908 \pm 1.7173$ & $-2.4403 *$ & $0.2051 \pm 0.0743$ & 2.7596 & $0.0032 \pm 0.1539$ & 0.0206 \\
$c h$ & $-0.6605 \pm 0.3354$ & -1.9694 & $-14.4373 \pm 7.2165$ & -2.0006 & $0.2627 \pm 0.2499$ & 1.0510 & $0.5399 \pm 0.2716$ & 1.9879 \\
$d m$ & $0.1751 \pm 0.0937$ & 1.8689 & $-1.2915 \pm 1.4846$ & -0.8699 & $-0.0779 \pm 0.0535$ & -1.4556 & $-0.0626 \pm 0.1029$ & -0.6077 \\
$h m$ & $0.1218 \pm 0.0987$ & 1.2340 & $1.3071 \pm 1.6663$ & 0.7844 & $-0.1851 \pm 0.0571$ & -3.2379 & $0.1472 \pm 0.1235$ & 1.1917 \\
$\chi_{(5)}^{2}$ & 24.8797 & & 13.9496 & & 35.2062 & & 14.8993 & \\
\hline
\end{tabular}

$c d$ - interaction between cytoplasm and the additive (d) nuclear-determined effect, $c h$ - interaction between cytoplasm and the dominance (h) nuclear-determined effect, $d$-additive genetic component, $d m$ - maternal effects traceable to the additive genetic component, $h$ - dominance, $h m$ - dominance effects of the maternal genotype, $i$ - additive by additive interaction, $j$ - additive by dominance interaction, $l$ - dominance by dominance interaction, $m$ - population mean. Chi-square test for the goodness of fit was not significant $(\mathrm{p}>0.01) .{ }^{*} \mathrm{p}<0.01$.

rice (Abe and Futsuhara, 1991), maize (Petolino and Thompson, 1987), winter wheat (Ou et al., 1989), Allium ampeloprasum (Silverstand et al., 1995), Helianthus annuus L (Sarrafi et al., 1996), eggplant (Chakravarthi et al., 2010) and rapeseed (Etedal et al., 2012).

Based on Hayman's analysis, significant additive genetic variation was observed for all of the four in vitro characters. The most striking feature observed was the presence of highly significant average reciprocal effects (c) for embryogenic callus quantity and regeneration frequency. The $d$ component was also significant for all of the characters studied.

Our results revealed that embryogenic callus quantity and regeneration frequency showed a good fit to the genetic model of Mather and Jinks (1982), whereas for the other two characters (total callus quantity and growth rate), this model was not a good fit, as indicated by the highly significant $X^{2}$ values (Table 4).

For embryogenic callus quantity, the estimates (additive) and (additive $\mathrm{x}$ dominance) were significant among the nuclear parameters. The interaction between the cytoplasm and nuclear additive component (' $c d$ ') was also significant. These findings suggested that the reciprocal differences for embryogenic callus quantity could be attributed to the interaction between cytoplasmic and nuclear determinants. Narasimhulu et al. (1989) reported a similar observation for shoot morphogenesis in Brassica spp. and suggested that both cytoplasm and nuclear genomes contain determinants important for temporal regulation and co-ordinated synthesis of factors that promote shoot mor- 
phogenesis. Janila et al. (2013), based on genetic analyses of resistance to late leaf spot (LLS) in interspecific hybrids of groundnut, reported that a combination of nuclear and maternal gene effects was involved in the resistance factor.

For regeneration frequency in which the additivedominance model was adequate, five out of the 11 estimates were significant, confirming the predominant role of nuclear gene control in the expression of this character. The positive $(h)$ increment of loci and the negative $(l)$ increments for pairs of loci suggested the occurrence of nonallelic interaction of the duplicate kind in the expression of this character. This type of duplicate epistasis was considered to be associated with characters expressed in directional selection (Powell and Caligari, 1987). As inferred from the work of Satyavathi et al. (2006), regeneration frequency is associated with the $d_{2}$ gene that controls the dwarf nature of the plant. The suggestion by Powell and Caligari (1987) regarding the operation of directional selection is consistent with the origin of $\mathrm{P}_{3}\left(d_{2}\right.$ dwarf line $)$ developed by Burton and Fortson (1966) and the association or linkage between the $d_{2}$ locus and loci controlling in vitro regeneration frequency. The $\mathrm{P}_{3}$ line was the result of breeders selecting for homozygosis dwarf stature $\left(d_{2} d_{2}\right)$, i.e., unidirectional selection for reduction in height. Since at least some of the loci controlling in vitro regeneration are linked to the $d_{2}$ locus, the selection for dwarfism might also have indirectly affected the linked loci for regeneration.

Both linkage and selection (direct and indirect) for the two characters (dwarf nature and regeneration) might have resulted in the characteristic and visually identifiable callus morphology noted in the dwarf parent. For Cyclamen persicum, Pueschel et al. (2003) postulated a hypothesis of two dominant epistatic genes controlling the capacity for regeneration and stated that the trait can easily be integrated into other genotypes of economic interest by crossings. Moreover, linked DNA-markers would enable early selection of desired genotypes capable of regenerating somatic embryos and would spare the time and labor involved in in vitro screening. Dodig et al. (2008) studied the correlation between tissue culture and agronomic traits in wheat. Agronomic traits with highly positive direct effects on tissue culture traits were considered as suitable predictors of good in vitro plant regeneration. These authors found productive tillering to have a significant (positive) direct effect on all tissue culture traits.

Our study revealed that for two characters, embryogenic callus quantity and regeneration frequency, the former showed a greater proportion of cytoplasmic nuclear interaction whereas the latter showed a greater role of nuclear factors. Mathias et al. (1986) reported the role of specific interactions between the nuclear and cytoplasm in determining tissue culture responses in Chinese spring wheat. The possibility that regeneration from tissue culture is partly controlled by specific nuclear-cytoplasmic interactions has also been suggested by Henry et al. (1994).
Since the regeneration frequency is dependent upon embryogenic callus quantity, the $d_{2}$ cytoplasm might also contribute (in addition to directional selection and linkage) to the characteristic response and morphological appearance of the callus in dwarf parents. This conclusion raises the possibility of manipulating these in vitro characters through the selection of appropriate lineages, despite their complex inheritance patterns.

\section{Acknowledgments}

The authors thank the University Grants Commission, Government of India for the Junior and Senior Research Fellowship to VVS.

\section{References}

Abe T and Futsuhara Y (1991) Diallel analysis of callus growth and plant regeneration in rice seed-callus. Jpn J Genet 66:129-140.

Bebeli PJ (1995) Cytoplasmic effects on tissue culture response in wheat. J Genet Breed 49:201-208.

Ben-Amer IM and Boner A (1997) Effect of cytoplasm on immature embryo culture in wheat (Triticum aestivum L.). Cereal Res Commun 25:135-140.

Burton GW and Fortson JC (1966) Inheritance and utilization of five dwarfs in pearl millet (Pennisetum typhoides) breeding. Crop Sci 6:69-72.

Cavalli LL (1952) An analysis of linkage in quantitative inheritance. In: Rieve ECR and Waddington CH (eds) Quantitative Inheritance, HMSO, London, pp 135-144.

Chakravarthi DVN,Rao YV,Rao MVS and Manga V (2010) Genetic analysis of in vitro callus and production of multiple shoots in eggplant. Plant Cell Tissue Organ Cult 102:87-97.

Dodig D, Zoric M, Mitic N, Nikolic R, King SR, Lalevic B and Surlan-Momirovic G (2008) Tissue culture and agronomic traits relationship in wheat. Plant Cell Tissue Organ Cult 95:107-114.

Ekiz A and Konzak CF (1991) Nuclear and cytoplasmic control of anther culture response in wheat: I. Analysis of alloplasmic lines. Crop Sci 31:1421-1427.

Etedal F, Khandan A, Motalebi-Azar A, Hasanzadeh Z, Sadeghan A, Pezeshki A, Pezeshki A and Kazemiani S (2012) Biometric-genetic analysis of in vitro callus proliferation in rapeseed (Brassica napus). Afr J Agric Res 48:6474-6478.

Foroughi-Wehr B, Friedt W and Wenzel G (1982) On the genetic improvement of androgenetic haploid formation in Hordeum vulgare L. Theor Appl Genet 62:233-239.

Ge YX, Wei JL, Lu MY and Wei JK (1994) Studies on the in vitro culture of immature embryos of homonuclear-heterocytoplasmic maize lines. Acta Agric Univ Pekinensis 20:397401.

Griffing B (1956) Concept of general and specific combining ability in relation to diallel crossing systems.Aust $\mathrm{J}$ Biol Sci9:463-493.

Hayman BI (1954a) The analysis of variance of diallel tables. Biometrics 10:235-244.

Hayman BI (1954b) The theory and analysis of diallel crosses. Genetics 39:789-809. 
Hayman BI (1958) The separation of epistatic from additive and dominance variation in generation mean. Heredity 12:371390.

Henry Y, Vain P and de Buyser J (1994) Genetic analysis of in vitro plant tissue culture responses and regeneration capacities. Euphytica 79:45-58.

Hou L, Ultrich SE and Kleinhofs A (1994) Inheritance of anther culture traits in barley. Crop Sci 34:1243-1247.

Ikeuchi M, Sugimoto K andIwase A (2013) Plant callus: mechanisms of induction and repression. Plant Cell 9:3159-3173.

Janila P, Ramaiah V,Rathore A, Rupakula A, Reddy KR, Waliyar F and Nigam SN (2013) Genetic analysis of resistance to late leaf spot in interspecific groundnuts. Euphytica 193:13-25.

Jinks JL (1964) Extra Chromosomal Inheritance. Prentice Hall, London, $177 \mathrm{p}$.

Keyes GJ, Collins GB and Taylor NL (1980) Genetic variation in tissue cultures of red clover. Theor Appl Genet 58:265-271.

Krottje PA, Wofford DS and Quesenberry KH (1996) Heritability estimates for callus growth and regeneration in Desmodium. Theor Appl Genet 93:568-573.

Li Z, Duan S, Kong J, Li S, Li Y and Zhu Y (2007) A single genetic locus in chromosome 1 controls conditional browing during the induction of calli from mature seeds of Oryza sativa ssp. Indica. Plant Cell Tissue Organ Cult 89:237-245.

Mather K and Jinks JL (1982) Biometrical Genetics. $3^{\text {rd }}$ edition. Chapman and Hall, London, 396 p.

Mathias RJ, Fukui K and Law CN (1986) Cytoplasmic effects on the tissue culture response of wheat (Triticum aestivum) callus. Theor Appl Genet 72:70-75.

Murashige T and Skoog F (1962) A revised medium for rapid growth and bioassays with tobacco tissue cultures. Physiol Plant 15:473-497.

Mythili PK, Satyavathi V, Pavan Kumar G, Rao MVS and Manga V (1997) Genetic analysis of short term callus culture and morphogenesis in pearl millet, Pennisetum glaucum. Plant Cell Tissue Organ Culture 50:139-142.

Narasimhulu SB, Chopra VL and Shyam Prakash (1989) The influence of cytoplasmic differences on shoot morphogenesis in Brassica carinata A. Br. Euphytica 40:241-243.

Ou G, Wang WC and Nguyan HT (1989) Inheritance of somatic embryogenesis and organ regeneration from immature embryo cultures of winter wheat. Theor Appl Genet 78:137142.

Petolino JF and Thompson SA (1987) Genetic analysis of anther culture response in maize. Theor Appl Genet 74:284-286.

Powell W (1988) Diallel analysis of barley anther culture response. Genome 30:152-157.
Powell W and Caligari PDS (1987) The in vitro genetics of barley (Hordeum vulgare L.): detection and analysis of reciprocal differences for culture response to 2,4-dichlorophenoxyacetic acid. Heredity 59:293-299.

Pueschel AK, Schwenkel HG and Winkelmann T (2003) Inheritance of the ability for regeneration via somatic embryogenesis in Cyclamen persicum. Plant Cell Tissue Organ Culture 72:43-51.

Sarrafi A, Roustan JP, Fallot J and Alibert G (1996) Genetic analysis of organogenesis in the cotyledons of zygotic embryos of sunflower (Helianthus annuus L.). Theor Appl Genet 92:225-229.

Satyavathi VV, Subbarao MV, Manga V and Chittibabu M (2006) Genetics of some in vitro characters in pearl millet. Euphytica 148:243-249.

Silverstand CHJ, Jacobsen E and Van Harten AM (1995) Genetic variation and control of plant regeneration in leek (Allium ampeloprasum L.). Plant Breed 114:333-336.

Singsit C and Veilleux RE (1989) Intra and inter specific transmission of androgenetic competence in diploid potato species. Euphytica 43:105-112.

Taylor TE and Veilleux RE (1992) Inheritance of competences for leaf disc regeneration, anther culture and protoplast culture in Solanum phureja and correlations among them. Plant Cell Tissue Organ Cult 31:95-103.

Tomes DT and Smith OS (1985) The effect of parental genotype on initiation of embryogenic callus from elite maize (Zea mays L.) germplasm. Theor Appl Genet 70:505-509.

Walton PD and Brown DC (1988) Screening Medicago wild species for callus formation and the genetics of somatic embryogenesis. J Genet 67:95-100.

Wan Y, Sorrensen Y and Liang GH (1988) Genetic control of in vitro regeneration in alfalfa (Medicago sativa L.). Euphytica 39:3-9.

Wang X, Wu R, Lin X, Bai Y, Song C, Yu X, Xu C, Zhao N, Dong $\mathrm{Y}$ and Liu B (2013) Tissue culture-induced genetic and epigenetic alterations in rice pure-lines, $\mathrm{F}_{1}$ hybrids and polyploids. BMC Plant Biol 13:e77.

Willman MR, Schroll SM and Hodges TK (1989) Inheritance of somatic embryogenesis and plantlet regeneration from primary (Type I) callus in maize. In Vitro Cell Dev Biol Plant 25:95-100.

\section{Associate Editor: Everaldo Gonçalves de Barros}

License information: This is an open-access article distributed under the terms of the Creative Commons Attribution License (type CC-BY), which permits unrestricted use, distribution and reproduction in any medium, provided the original article is properly cited. 